\title{
BRASIL E CHILE: UM ESTUDO COMPARADO SOBRE O RECONHECIMENTO DA UNIÃO ESTÁVEL
}

\author{
Grasiele Augusta Ferreira Nascimento ${ }^{1}$ \\ Francisco Javier Talep Pardo ${ }^{2}$
}

\section{Resumo}

O presente trabalho tem como objetivo realizar um estudo comparado sobre o reconhecimento da união estável no Brasil e no Chile, através da análise da Constituição da República Federativa do Brasil, do Código Civil e jurisprudência dos tribunais brasileiros, e da Lei 20.830, de 21/04/2015, que criou o Acordo de União Civil no Chile. O estudo é realizado por meio do método teórico-documental, numa perspectiva comparada, no intuito de perceber as semelhanças e diferenças do instituto da união estável nos dois países.

Palavras-chave: União estável. União civil. Acordo de união civil. Estudo comparado.

\section{BRAZIL AND CHILE: A COMPARATIVE STUDY ON THE RECOGNITION OF THE STABLE UNION}

\begin{abstract}
The objective of this study is to conduct a comparative study on the recognition of the stable union in Brazil and Chile, through the analysis of the Constitution of the Federative Republic of Brazil, Civil Code and the jurisprudence of the Brazilian courts, and Law 20.830 of 04/21/2015, which created the civil union agreement in Chile. The study is carried out by means of the theoretical-documentary method, in a comparative perspective, in order to perceive the similarities and differences of the institute of the stable union in the two countries.
\end{abstract}

Keywords: Stable union. Civil union. Civil union agreement. Comparative study.

\section{Introdução}

A sociedade ocidental nas últimas décadas tem sido abalada por várias mudanças em seus paradigmas sociais e, em particular, no campo da família; de modo que legisla sobre o casamento homoafetivo, adoção de crianças por casais do mesmo sexo, acordos de uniões civis, para citar alguns, que até algumas décadas atrás teria sido uma extravagância.

Acompanhando as mudanças sociais, frutos da padronização dos comportamentos na era da globalização, países como Brasil e Chile deram passos

\footnotetext{
1 Pós-doutora em Democracia e Direitos Humanos pela Universidade de Coimbra/Ius Gentium Conimbrigae (2014), Doutora em Direito pela Pontifícia Universidade Católica de São Paulo. Diretora Operacional do Centro Universitário Salesiano de São Paulo (UNISAL). Professora do Programa de Mestrado em Direito. Professora Assistente Doutora da Faculdade de Engenharia de Guaratinguetá (FEG/UNESP).

Advogado. Mestre em Direito pela Escuela de Derecho de la Universidad de Chile. Professor da Universidad Central de Chile (UCEN).
} 
significativos nas últimas décadas a respeito do reconhecimento de mudanças familiares, embora em velocidades distintas.

No Brasil, o reconhecimento da união estável apenas ocorreu de forma expressa com o advento da Constituição Federal de 1988, embora já fosse observado indiretamente em algumas leis e decisões do Supremo Tribunal Federal. A partir de então, a legislação brasileira, assim como os tribunais superiores, passaram a reconhecer e a regulamentar as diversas formas de constituições familiares e seus desdobramentos.

O Chile, imerso nesta visão global que não tem fronteiras, não podia ficar alheio a essa influência, e assim, mesmo que lentamente, em principio, para chegar à formalidade de hoje, nasceram diferentes grupos que sediaram este pensamento mais moderno, impondo-o como argumento para a discussão social.

No entanto, a sociedade chilena, ainda conservadora, somente deu tímidos passos tendentes a acolher aqueles pensamentos mais radicais (casamento homoafetivo, por exemplo) que já estão nas leis em vários países de nossa órbita ocidental. Uma delas, que foi o resultado de um longo desejo por esses novos grupos de pressão social, é o contrato de acordo de união civil.

O presente artigo, o qual não se destina a aprofundar juízos de valor, ou questões axiológicas, objetiva realizar um estudo comparado entre o instituto da união estável no Brasil e no Chile, apontando, de maneira crítica e pormenorizada, nossas apreensões sobre o trabalho legislativo que resultou no chamado contrato de acordo de união civil chileno.

O estudo será realizado por meio do método teórico-documental, numa perspectiva comparada, no intuito de perceber as semelhanças e diferenças do instituto da união estável nos dois países.

Em relação à legislação chilena, a análise será realizada a partir da Lei 20.830, de 21 de abril de 2015, que entrou em vigor em 22 de outubro do mesmo ano, concentrandose nos problemas mais questionáveis do ponto de vista da técnica legislativa, na busca da efetiva segurança jurídica.

\section{União Estável no ordenamento jurídico brasileiro}

O reconhecimento das diversas constituições familiares no Brasil percorreu um longo caminho.

Historicamente, pela forte influência da Igreja Católica, o casamento religioso era o único reconhecido pelo Direito Canônico. Em termos legislativos, o casamento civil apenas foi regulado pelo Decreto n. 181, no ano de 1890, tendo sido reconhecido como única forma de constituição familiar pela Constituição Republicana de 1891 e pelo Código Civil de 2016.

Com as mudanças culturais vivenciadas pela sociedade brasileira, surgiram outras formas de constituição familiar e, com elas, novos dispositivos legais que pudessem contemplar os anseios da população. 
Neste sentido, a própria Constituição Federal de 1988 reconheceu três modelos de arranjos familiares: a família matrimonial, decorrente do casamento civil; convivencional, fruto da união estável; e monoparental, reconhecendo como entidade familiar a comunidade formada por qualquer dos pais e seus descendentes.(GAGLIANO; PAMPLONA FILHO, 2011, P. 406).

Sobre o tema, assim dispôs o texto constitucional:

Art. 226. A família, base da sociedade, tem especial proteção do Estado.
$\S 1^{\circ}$ O casamento é civil e gratuita a celebração.
$\S 2^{\circ}$ O casamento religioso tem efeito civil, nos termos da lei.
$\S 3^{\circ}$ Para efeito da proteção do Estado, é reconhecida a união estável entre o
homem e a mulher como entidade familiar, devendo a lei facilitar sua
conversão em casamento.

$\S 4^{\circ}$ Entende-se, também, como entidade familiar a comunidade formada por qualquer dos pais e seus descendentes.

$\S 5^{\circ}$ Os direitos e deveres referentes à sociedade conjugal são exercidos igualmente pelo homem e pela mulher.

$\S 6^{\circ} \mathrm{O}$ casamento civil pode ser dissolvido pelo divórcio.

$\S 7^{\circ}$ Fundado nos princípios da dignidade da pessoa humana e da paternidade responsável, o planejamento familiar é livre decisão do casal, competindo ao Estado propiciar recursos educacionais e científicos para o exercício desse direito, vedada qualquer forma coercitiva por parte de instituições oficiais ou privadas.

$\S 8^{\circ} \mathrm{O}$ Estado assegurará a assistência à família na pessoa de cada um dos que a integram, criando mecanismos para coibir a violência no âmbito de suas relações.

Desta forma, o reconhecimento da união estável, enquanto entidade familiar, apenas ocorreu com a promulgação da Constituição Federal de 1988, após percorrer um longo caminho, enfrentando posicionamentos conversadores e religiosos. Neste trajeto, o instituto percorreu as seguintes fases:

$1^{\text {a })}$ ausência absoluta de tutela jurídica - nesta fase, que perdurou até início do século $\mathrm{XX}$, os relacionamentos sem vínculo matrimonial eram absolutamente ilícitos e proibidos, considerados como relacionamentos adúlteros;

$2^{\mathrm{a}}$ ) aceitação natural como fato social ou de tolerância - refletindo a realidade social, tem-se início a aceitação da união sem vínculo matrimonial. 
Surge a lei previdenciária n. 4.297/1963, a qual reconhecia o direito de recebimento de pensão por morte à companheira, desde que a relação tivesse perdurado pelo prazo não inferior a cinco anos até o falecimento do companheiro.

Além disso, passou-se a considerar que o trabalho desenvolvido pela companheira no cuidado da casa e dos filhos ensejaria um enriquecimento ilícito do homem. Em virtude desta interpretação, a ex-companheira passou a receber indenização pelos serviços domésticos prestados durante a convivência. Com o passar dos anos, em meados de 1964, a mulher deixou de ser considerada prestadora doméstica e passou a ser reconhecida como sócia da relação de concubinato.

$3^{\text {a }) ~ r e c o n h e c i m e n t o ~ c o n s t i t u c i o n a l ~ c o m o ~ e n t i d a d e ~ f a m i l i a r ~-~ s o m e n t e ~ c o m ~ a ~ C o n s t i t u i c ̧ a ̃ o ~}$ Federal de 1988 a união estável foi reconhecida como entidade familiar, nos seguintes

termos: "Para efeito da proteção do Estado, é reconhecida a união estável entre o homem e a mulher como entidade familiar, devendo a lei facilitar sua conversão em casamento.” (art. 226, § $3^{\circ}$ ).

Como a Constituição Federal foi promulgada em 1988 e o Código Civil só fora atualizado em 2002, a primeira regulamentação do parágrafo $3^{\circ}$ do art. 226 se deu por meio da Lei n. 8.971, de 29 de dezembro de 1994, que regulou o direito dos companheiros a alimentos e à sucessão. Note-se que o art. $1^{\circ}$ do mencionado dispositivo estabelece alguns requisitos não expressos no texto constitucional, como, por exemplo, o tempo de convivência e a existência de filhos." (DIAS; LEAL, 2016, p. 96).

Posteriormente, a Lei n. 9.278/1996, trouxe novas regulamentações sobre a união estável, a qual passou a ser conceituada como a "convivencia duradoura, pública e contínua, de um homem e uma mulher, estabelecida com o objetivo de constituição de família". (DIAS; LEAL, 2016, p. 96).

O Código Civil de 2002, por sua vez, dedicou cinco artigos à união estável, a saber:

Art. 1.723. É reconhecida como entidade familiar a união estável entre o homem e a mulher, configurada na convivência pública, contínua e duradoura e estabelecida com o objetivo de constituição de família.

$\S 1^{\mathrm{o}}$ A união estável não se constituirá se ocorrerem os impedimentos do art. 1.521; não se aplicando a incidência do inciso VI no caso de a pessoa casada se achar separada de fato ou judicialmente.

$\S 2^{\underline{0}}$ As causas suspensivas do art. 1.523 não impedirão a caracterização da união estável.

Art. 1.724. As relações pessoais entre os companheiros obedecerão aos deveres de lealdade, respeito e assistência, e de guarda, sustento e educação dos filhos. 
Art. 1.725. Na união estável, salvo contrato escrito entre os companheiros, aplica-se às relações patrimoniais, no que couber, o regime da comunhão parcial de bens.

Art. 1.726. A união estável poderá converter-se em casamento, mediante pedido dos companheiros ao juiz e assento no Registro Civil.

Art. 1.727. As relações não eventuais entre o homem e a mulher, impedidos de casar, constituem concubinato.

Pela análise da legislação brasileira atual, podemos apontar como requisitos para a configuração da união estável, em primeiro lugar, a existência de união, a qual pela redação da Constituição Federal, repetida pelo Código Civil, deveria ser entre um homem e uma mulher. Este entendimento, porém, foi alterado pelo julgamento da ADI 4277/DF, no qual o Supremo Tribunal Federal considerou viável a união entre pessoas do mesmo sexo. (DIAS; LEAL, 2016, p. 97). Após inúmeras discussões sobre o tema, o STF reconheceu a união homoafetiva, na busca da concretização da dignidade da pessoa humana. Atualmente, o reconhecimento de uniões homoafetivas já está pacificado pelos tribunais superiores.

Além disso, para o reconhecimento da união estável, a convivência deve ser pública, contínua e duradora, com o objetivo de formar uma família. Assim sendo, as relações esporádicas e os namoros não preenchem os requisitos para a sua caracterização.

Diferentemente do previsto na lei chilena que criou o Acordo de União Civil, a legislação brasileira não exige qualquer formalidade para a caracterização da união estável, o que, na prática, pode gerar dificuldade de comprovação de sua existência pública. Nada impede, porém, que seja firmado compromisso pelos conviventes perante o Cartório de Notas, promovendo uma escritura pública de união estável. Os conviventes deverão apresentar documentos de identidade e duas testemunhas que comprovem a união do casal.

A união estável assegura direitos e deveres entre os conviventes. Entre os deveres, destacam-se a lealdade, o respeito, a assistência mútua material e moral, a responsabilidade pela guarda, assim como o sustento e educação dos filhos na proporção dos ganhos de cada convivente (DINIZ, 201, p. 445).

Vários são os direitos dos conviventes, dentre os quais destacamos: garantia à companheira mantida pela vítima de acidente de trabalho aos mesmos direitos da esposa; pagamento de pensão deixada pelo servidor civil e militar; possibilidade de abatimento no imposto sobre a renda em virtude da dependência do convivente; entendimento do companheiro como beneficiário no regime da previdência social, entre outros. Vale destacar, também, a recente decisão do Supremo Tribunal Federal, que reconheceu o mesmo direito sucessório dos casamentos às uniões estáveis, incluindo casais heterossexuais e homossexuais, correspondendo a $50 \%$ do patrimônio. "Com isso, os ministros declararam inconstitucional o artigo 1.790 do Código Civil, que determina que o companheiro receba $30 \%$ da herança" (CASADO, 2017). 
Sem dúvida, o reconhecimento da união estável pela legislação brasileira representou um grande avanço para a sociedade, embora já comecem a surgir novos arranjos familiares, como os poliafetivos, os quais exigirão novos estudos.

\section{União Civil no Chile: análise crítica da Lei 20.830, de 21 de abril de 2015 ("Acuerdo de Unión Civil")}

A Lei 20.830, de 21 de abril de 2015, a qual entrou em vigor em 22 de outubro do mesmo ano, criou e regulamentou o "Acordo de União Civil" no Chile.

De acordo com o disposto na Lei (art. $1^{03}$ ), o acordo de união civil é um contrato celebrado entre duas pessoas que dividem uma casa, com o propósito de regular os efeitos jurídicos oriundos de uma vida afetiva em comum, de caráter estável e permanente.

Embora seja um avanço na legislação chilena, cuja sociedade é historicamente conservadora, a referida lei apresenta alguns problemas de ordem técnica.

O Título I da Lei 20.830/2015 refere-se ao "acordo de união civil e coabitação civil". Neste título, algumas características são notadas:

Em primeiro lugar, a lei não define o Acordo de União Civil (AUC), embora afirme ser um contrato.

Trata-se de um contrato típico de Direito de Família, embora apresente características de um contrato patrimonial, tomando como base o disposto no art. 14 da mencionada lei, o qual estabelece que os conviventes civis deverão ajudar-se mutuamente e serão responsáveis pelos gastos originários da vida em comum (ORREGO, 2016).

Por outro lado, o mesmo artigo $1^{\circ}$ utiliza a expressão "casa", a qual não é utilizada pelo Código Civil chileno, deixando dúvidas sobre a sua amplitude. Desta forma, qual a razão da não utilização de expressões como residência, domicílio ou habitação, já reconhecidas pela legislação civil chilena?

Esta lei também visa regulamentar os efeitos jurídicos da vida afetiva conjunta do casal, de caráter estável e permanente, o que nos parece irrelevante, porque não constitui requisito de nenhuma natureza para este contrato.

$\mathrm{O}$ artigo $4^{\circ}$ estabelece que haverá parentesco por afinidade entre um convivente civil e os consanguíneos da pessoa com a qual esteja vivendo em união civil, através de contrato, enquanto este estiver vigente.

O Título II da Lei 20.830/2015 é dedicado à celebração do acordo de união civil e seus requisitos de validade e proibições.

Deste título, podemos destacar que o Acordo, apesar de ter natureza contratual, é solene, devendo ser celebrado diante de um oficial de registro civil, não

\footnotetext{
3 "Artículo $1^{\circ}$.- El acuerdo de unión civil es un contrato celebrado entre dos personas que comparten un hogar, con el propósito de regular los efectos jurídicos derivados de su vida afectiva en común, de carácter estable y permanente. Los contrayentes se denominarán convivientes civiles y serán considerados parientes para los efectos previstos en el artículo 42 del Código Civil.

Su celebración conferirá el estado civil de conviviente civil. El término de este acuerdo restituirá a los contrayentes el estado civil que tenían antes de celebrar este contrato, salvo en la situación prevista en la letra c) del artículo 26.(...)".
} 
sendo necessária a presença de testemunha, como se exige para a formalização do casamento.

Assim como o contrato previsto no artigo 102 do Código Civil, pode ser celebrado por meio de um mandatário nomeado especialmente para este efeito.

No entanto, uma das disposições mais problemáticas deste título é a estabelecida no artigo $7^{\circ}$ da lei, o qual dispõe que para a validade do contrato de acordo de união civil, será necessário que os contraentes sejam maiores de idade e que tenham a livre administração de seus bens. Em outras palavras, os contraentes deverão ser plenamente capazes nos termos dos artigos 1446 e 1447 do Código Civil.

Contudo, o artigo acrescenta que o pródigo, considerado relativamente incapaz, pode celebrar o acordo de união civil. Desta forma, a segunda parte do artigo $7^{\circ}$ se torna de difícil compreensão, já que ela afetaria somente o pródigo (descartartando o insano, surdos ou surdos-mudos que não podem ser claramente entendidos, maiores de idade, toda vez que estes sejam absolutamente incapazes e se encontrem inabilitados de celebrar qualquer tipo de ato).

A partir desta possibilidade, surgem vários questionamentos que deverão ser resolvidos pelos tribunais, como, por exemplo, como seria o procedimento no caso de ambos os contraentes serem pródigos: necessitam de autorização ou representação para celebrar o contrato de união civil? Quem deveria administrar os bens?

$\mathrm{O}$ artigo $9^{\circ}$ da lei em estudo repete parágrafo $1^{\circ}$ do artigo $6^{\circ}$ da Lei 19.947 , em relação ao impedimento relativo ao parentesco, estabelecendo que não poderão celebrar o contrato de união civil os ascendentes e descendentes por consanguinidade ou afinidade, nem os colaterais por consanguinidade em segundo grau. Também não poderão celebrar o referido contrato as pessoas que se encontrem ligadas por um vínculo matrimonial não desfeito ou um acordo de união civil vigente.

O Título III da Lei 20.830/2015 abrange "acordos de União Civil detidos no exterior".

$\mathrm{O}$ artigo 12 da mencionada Lei aprova as regras gerais do direito internacional sobre o assunto, ou seja, "lex lócus regit actum", a respeito dos aspectos formais do ato; assim, remete às exigências da legislação chilena, regulação 2 do referido artigo 12.

Merece destaque a terceira regra trazida no artigo 12, a qual estabelece que, para que o acordo constituído em país estrangeiro produza efeitos no Chile, deverá estar inscrita no Registro Especial de acordos de união civil, previsto no artigo $6^{\circ}$ da lei em estudo. Os efeitos deste acordo, desde que cumpridas as exigências legais, se equipararão às leis chilenas, também se os contratantes forem estrangeiros e não residirem no território chileno. Mas o registro deverá ser formalizado em qual localidade?

Como o texto legal não é claro, devemos entender que a regra é repetida, no que diz respeito ao casamento, ou seja, o $1^{\circ}$ Distrito do Município de Santiago (Recoleta) ou pode ser qualquer parte do território da República?

$\mathrm{O}$ artigo 13 regula o aspecto patrimonial destes acordos, observando que para os acordos celebrados no exterior prevalecerá a regra da separação de bens, a menos que as partes pactuem a comunhão de bens. Esta regra é semelhante à regra relativa ao casamento.

O Título IV da lei de Acordo de União Civil é intitulado "Acordo dos efeitos da união civil".

Não é novidade esclarecer que, em matéria de direito privado, sempre as mais notáveis de qualquer instituição encontra-se nos efeitos jurídicos desta e, obviamente, o acordo de união civil não é exceção. 
O artigo 14 estabelece que os efeitos principais do Acordo de União Civil são: a "ajuda mútua" e a responsabilidade de "cobrir as despesas geradas a partir de vida em comum". Isto é curioso, uma vez que, analisando o artigo $1^{\circ}$ desse corpo legal, pareceria típico do direito da família, no entanto, a redação desta disposição parece mais como um contrato típico de âmbito patrimonial.

$\mathrm{O}$ artigo $15^{4}$ fala da gestão da propriedade. Parece certo que o regime jurídico seja da livre administração do patrimônio. No entanto, parece desastroso ter sido dada a oportunidade às partes de optar por comunhão de bens como uma alternativa.

$\mathrm{Na}$ verdade, poderia ter optado por um sistema semelhante ao da sociedade conjugal, que é mais vantajosa para aquele contratante que não trabalhará ou ganhará menos recursos econômicos que o outro.

Além disso, para adicionar mais dificuldades, é dada a opção de substituir a administração do patrimônio pela total separação por meio de escritura pública.

\footnotetext{
4 Artículo 15.- Los convivientes civiles conservarán la propiedad, goce y administración de los bienes adquiridos a cualquier título antes de la celebración del contrato y de los que adquieran durante la vigencia de éste, a menos que se sometan de manera expresa a las reglas que se establecen a continuación, las que deberán ser acordadas por los contrayentes al momento de celebrarse el acuerdo de unión civil. De este pacto se dejará constancia en el acta y registro que se indica en el artículo $6^{\circ}$.
}

$1^{a}$. Los bienes adquiridos a título oneroso durante la vigencia del acuerdo se considerarán indivisos por mitades entre los convivientes civiles, excepto los muebles de uso personal necesario del conviviente que los ha adquirido.

$2^{\text {a }}$. Para efectos de esta ley, se tendrá por fecha de adquisición de los bienes aquella en que el título haya sido otorgado.

$3^{\text {a }}$. Se aplicarán a la comunidad formada por los bienes a que se refiere este artículo las reglas del Párrafo $3^{\circ}$ del Título XXXIV del Libro IV del Código Civil.

Si los convivientes civiles hubieren pactado el régimen de comunidad podrán sustituirlo por el de separación total de bienes.

El pacto que los convivientes civiles celebren para sustituir el régimen de comunidad deberá otorgarse por escritura pública y no surtirá efectos entre las partes ni respecto de terceros, sino desde que esa escritura se subinscriba al margen de la respectiva inscripción del acuerdo de unión civil. Esta subinscripción sólo podrá practicarse dentro de los treinta días siguientes a la fecha de la escritura en que se pacte la separación. El pacto que en ella conste no perjudicará, en caso alguno, los derechos válidamente adquiridos por terceros respecto de cada uno de los convivientes civiles.

En la escritura pública de separación total de bienes, los convivientes civiles podrán liquidar la comunidad, celebrar otros pactos lícitos o ambas cosas, pero todo ello no producirá efecto alguno entre las partes ni respecto de terceros, sino desde la subinscripción a que se refiere el inciso anterior.

Tratándose de uniones civiles o contratos equivalentes, que regulen la vida afectiva en común de dos personas del mismo o de distinto sexo, sujetos a registro y celebrados válidamente en el extranjero que no se encuentren inscritos en Chile, y que cumplan con los requisitos establecidos en esta ley, será menester proceder previamente a su inscripción en el registro especial que establece el artículo $6^{\circ}$ de esta ley. Mediante el reglamento señalado en el artículo 48 se determinará la forma en que se dará cumplimiento a lo establecido en este inciso.

Cualquiera sea el régimen de bienes que exista entre los convivientes civiles, tendrá aplicación lo dispuesto en los artículos 141 a 149 del Código Civil. 
Finalmente, e não menos controverso, é o disposto no último parágrafo do artigo em comentário, referente à aplicação dos artigos 141 a 149 do Código Civil aos acordos de união civil, a respeito da propriedade da família.

Talvez a mais importante determinação da lei em estudo seja o previsto no artigo 16. ${ }^{\circ}$, reconhecendo o gozo dos mesmos direitos que o cônjuge sobrevivente, com todos os alcances jurídicos. O legislador lançou, com esta regra, uma grande inquietude jurídica, e o fez de maneira precisa, sem deixar dúvidas ou levantar possíveis interpretações.

O Título V refere-se às "Disposições Gerais".

Entre elas, o artigo 22 dá competência para conhecer as questões que são promovidas em relação a este contrato para os Tribunais de Família.

Entendemos acertada a competência ser dos Tribunais de Família, particularmente quando se menciona a regulamentação dos derivados efeitos jurídicos de vida emocional estável e permanente das partes, embora o contrato ganhe nuances típicos dos direitos econômicos, de competência dos Tribunais Civis.

O término do acordo de união civil foi previsto no Título VI da lei em estudo. Trata-se de um título bastante nebuloso, diante dos problemas práticos que podem acarretar.

Artigo $26^{5}$ concentra todos os modos de extinção do contrato de união civil.

${ }^{5}$ Artículo 26.- El acuerdo de unión civil terminará:

a) Por muerte natural de uno de los convivientes civiles.

b) Por muerte presunta de uno de los convivientes civiles, de conformidad a lo dispuesto en el artículo 43 de la ley $\mathrm{N}^{\circ} 19.947$, sobre matrimonio civil. Terminará también por la comprobación judicial de la muerte de uno de los convivientes civiles efectuada por el juez del último domicilio que el difunto haya tenido en Chile, en los términos prescritos en los artículos 95 y 96 del Código Civil. c) Por el matrimonio de los convivientes civiles entre sí, cuando proceda. d) Por mutuo acuerdo de los convivientes civiles, que deberá constar por escritura pública o acta otorgada ante oficial del Registro Civil.

e) Por voluntad unilateral de uno de los convivientes civiles, que deberá constar por escritura pública o acta otorgada ante oficial del Registro Civil.

En cualquiera de estos casos, deberá notificarse al otro conviviente civil, mediante gestión voluntaria ante el tribunal con competencia en materias de familia, en la que podrá comparecer personalmente.

La notificación deberá practicarse por medio de receptor judicial, dentro de los veinte días hábiles siguientes a la subinscripción de la referida escritura o acta, al margen de la inscripción del acuerdo de unión civil, efectuada en el registro especial que establece el artículo $6^{\circ}$.

La falta de notificación no afectará el término del acuerdo de unión civil, pero hará responsable al contratante negligente de los perjuicios que la ignorancia de dicho término pueda ocasionar al otro contratante. Quedará relevado de esta obligación si el miembro de la pareja a quien debe notificarse se encuentra desaparecido, o se ignora su paradero o ha dejado de estar en comunicación con los suyos. En todo caso, no podrá alegarse ignorancia transcurridos tres meses de efectuada la subinscripción a que se refiere el inciso precedente.

f) Por declaración judicial de nulidad del acuerdo. La sentencia ejecutoriada en que se declare la nulidad del acuerdo de unión civil deberá subinscribirse al margen de la inscripción a que se hace mención en el artículo $6^{\circ}$ y no será oponible a terceros sino desde que esta subinscripción se verifique.

$\mathrm{El}$ acuerdo que no reúna los requisitos establecidos en los artículos $7^{\circ}, 8^{\circ}$ y $9^{\circ}$ de esta ley es nulo.

La acción de nulidad corresponderá a cualquiera de los presuntos convivientes civiles y sólo podrá ejercitarse mientras ambos vivan, salvo en las excepciones contempladas en los incisos siguientes.

Cuando el acuerdo haya sido celebrado por una persona menor de dieciocho años, la acción de nulidad sólo podrá ser intentada por ella o por sus ascendientes. En este caso, la acción de nulidad prescribirá al expirar el término de un año desde que el menor hubiese alcanzado la mayoría de edad.

Será también nulo el acuerdo celebrado mediante fuerza ejercida en contra de uno o de ambos contrayentes o cuando se ha incurrido en un error acerca de la identidad de la persona con la que se 
As alíneas "a" e "b" contemplam a morte (natural ou artificial) de um dos cônjuges como as primeiras causas de extinção do contrato. Em outras palavras, trata-se de contrato "intuito personae".

A alínea "c" contempla a possibilidade de casamento entre os conviventes. A novidade desta regra é que não se pode celebrar um casamento enquanto existir um vínculo de convivência civil vigente.

O acordo de união civil também poderá ser extinto de comum acordo entre os conviventes, nos termos da alínea "d" do artigo 26. Esta é a resposta ao estabelecido no Código Civil artigos 1545 e 1567 do parágrafo $1^{\circ}$, no sentido de aplicar o princípio geral de direito que afirma que "os contratos são desfeitos como são feitos".

No entanto, a causa mais problemática de extinção do acordo está previsto na alínea "e" do artigo 26, que é a vontade unilateral de um dos conviventes.

De fato, para que se opere esse motivo, é necessário que a vontade de uma das partes seja revelada através de escritura pública, ou seja, é solene e, no nosso entender, bastante razoável.

Em seguida, o texto legal acrescenta que, qualquer que seja o meio pelo qual ocorra a rescisão contratual, a outra parte convivente deverá ser notificada através do Tribunal de Família competente. Isso também é razoável, no entanto, o legislador não esclareceu qual tipo de notificação é válida. Neste sentido, resta a dúvida: A notificação deverá ser pessoal? Por voto?

De qualquer forma, a falta de notificação não afetará o término do acordo, mas responsabilizará o convivente pelos prejuízos causados ao outro, os quais poderão ser de caráter patrimonial ou moral, nos termos do artigo 2.314 do Código Civil.

Finalmente, a alínea "f" contempla a nulidade como outra causa de extinção. Que tipo de nulidade? Certamente não será a patrimonial, uma vez que o contrato de união civil pertence à matéria própria de Direito de Família. Em outras palavras, estamos testemunhando uma nova modalidade de nulidade para ser adicionada às modalidades já existentes na legislação civil chilena.

O artigo 27 se aplica aos motivos para a rescisão previstos nas alíneas "d”, "e" e "f" do n. 1 do Capítulo VII da Lei 19.947, em compensação econômica. Desta maneira, o convivente que não pode desenvolver atividade remunerada em virtude dos cuidados com a casa e os filhos, ou o fez em proporção mais desfavorável, receberá uma

contrata, caso en el cual la acción sólo podrá ser intentada por el afectado, dentro del plazo de un año contado desde que cese la fuerza o desde la celebración del acuerdo, en caso de error.

La muerte de uno de los convivientes civiles extingue la acción de nulidad, salvo cuando el acuerdo de unión civil haya sido celebrado en artículo de muerte, o que la causal que funde la acción sea la existencia de un vínculo matrimonial no disuelto o de otro acuerdo de unión civil vigente, casos en que la acción podrá ser intentada por los herederos del difunto dentro del plazo de un año contado desde el fallecimiento.

La acción de nulidad fundada en la existencia de un vínculo matrimonial no disuelto o de otro acuerdo de unión civil vigente corresponderá, también, al cónyuge o al conviviente civil anterior o a sus herederos.

Produciéndose la muerte de uno de los convivientes civiles después de notificada la demanda de nulidad, podrá el tribunal seguir conociendo de la acción y dictar sentencia definitiva sobre el fondo del asunto.

El término del acuerdo de unión civil por las causales señaladas en las letras d) y e) producirá efectos desde que la respectiva escritura pública o el acta otorgada ante el oficial del Registro Civil, según corresponda, se anote al margen de la inscripción del acuerdo de unión civil en el registro especial a que se hace mención en el artículo $6^{\circ}$. 
compensação econômica por ocasião do término do acordo nas hipóteses previstas nas mencionadas alíneas.

A medida é justa e razoável, no entanto, parece bastante ilusória, já que, na prática, este instituto pode prosperar sem que seja levado a juízo para reclamar por eventual compensação.

\section{Conclusões}

O reconhecimento da união estável seguiu caminhos e tempos distintos no Brasil e no Chile.

No Brasil, embora o reconhecimento da união estável tenha ocorrido de forma expressa apenas com o advento da Constituição Federal de 1988, embora já fosse observado indiretamente em algumas leis e decisões do Supremo Tribunal Federal, é certo que caminhou em passos mais largos e velozes daqueles contemplados pela legislação chilena.

De acordo com a análise pormenorizada da Lei 20.830/2015, que criou o Acordo de União Civil no Chile, em seus aspectos mais questionáveis, parece clara a sua qualidade legislativa precária; suas possíveis dificuldades práticas; os inconvenientes interpretativos que deverão necessariamente ser resolvidos por via jurisprudencial; a difícil discussão de resolver, em uma sociedade ainda muito conservadora, o reconhecimento do casamento igualitário (homoafetivo); e, o que é mais grave ainda, o silêncio sobre questões práticas que precisam de uma resposta, como, por exemplo: o que acontece com as compras entre os civis que vivem juntos?; Se o contrato é realizado entre conviventes do sexo oposto e o homem é declarado pródigo, as mulheres podem ser administradoras do patrimônio? Vale destacar que a lei chilena concede ao homem a responsabilidade pela administração do patrimônio do casal.

No entanto, embora seja um avanço em relação ao tema da união civil, podemos concluir que a referida lei apresenta inúmeras lacunas que ainda precisam ser sanadas.

De uma perspectiva contingente, considerando as características da sociedade chilena, acreditamos que esta lei que instituiu o Acordo de União Civil no Chile, embora tenha nascido sob o beiral do igualitarismo e, particularmente, acolhendo um anseio de grupos homossexuais, terá maior utilidade para casais heterossexuais que não queiram se casar, e para pessoas maduras que já tiveram experiência de viver outros relacionamentos.

Ousamos afirmar que o presente contrato não substituirá o matrimônio como instituição, nem como opção de vida em comum, mas será uma opção viável para casais que não queiram submeter-se às normas matrimoniais rígidas, e, particularmente, pela facilidade prevista para a sua dissolução, embora ainda seja necessário introduzir significativas mudanças que possam sanar as dúvidas deixadas pelo texto legal.

\section{Referências}

BARRIENTOS G., Javier. Código de la Familia. Santiago de Chile: Editorial Legal Publishing, 2015. 
BENEDITO, Luiza Machado Farhat; OLIVEIRA, Juliana Aparecida Gomes. A outorga uxória e união estável no novo Código de Processo Civil. IN: FIUZA, César Augusto de Castro; LIMA, Renata Albuquerque; RODRIGUES JUNIOR. Otavio Luiz. Direito Civil Contemporâneo. Florianópolis: CONPEDI, 2016. Disponível em: http://www.conpedi.org.br/publicacoes/y0ii48h0/vgn7y7g7/3R9skJ9C25Uc2Z1T.pdf. Acesso em: 18.abr.2017.

CAHALI, Yussef Said; CAHALI, Francisco José. Família e sucessões: entidades familiares. V. 2 - São Paulo: Revista dos Tribunais, 2011.

CASADO, Letícia. STF equipara os direitos de herança em união estável e casamento civil. Disponível em: http://www1.folha.uol.com.br/cotidiano/2017/05/1882922-stfequipara-os-direitos-de-heranca-em-uniao-estavel-e-casamento-civil.shtml. Acesso em: 14.maio.2017.

DIAS, Eduardo Rocha; LEAL, Luziane de Figueiredo Simão. União estável: a (in)pacificação nos Tribunais. IN: HIRONAKA, Giselda Maria Fernandes Novaes; POLI, Luciana Costa; SANCHES, Samyra Haydêe Farra Naspolini. Direito de Família e sucessões II. Florianópolis: CONPEDI, 2016. Disponível em: http://www.conpedi.org.br/publicacoes/02q8agmu/8v3pu3uq/1D23PNKy1aZ3daF6.pdf. Acesso em: 17.abr.2017.

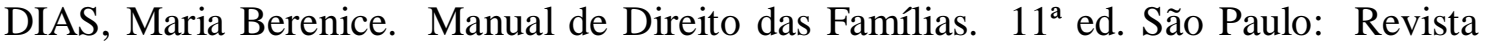
dos Tribunais, 2016.

DINIZ, Maria Helena. Curso de Direito Civil brasileiro. $31^{\text {a }}$ ed. São Paulo: Saraiva, 2017.

ESPINOZA, Diego Oliva. Análisis comparativo entre el matrimonio y el Acuerdo de Unión Civil en Derecho Internacional Privado. Revista de Estudios Ius Novum. Disponível em: www.leychile.cl/Navegar/scripts/.../10221.3/45283/1/HL20830.pdf. Acesso em: 08.mar.2017.

GAGLIANO, Pablo Stolze; PAMPLONA FILHO, Rodolfo. Novo Curso de Direito Civil - Direito de Família. São Paulo: Saraiva, 2011. V. VI.

HERNANDEZ PAULSEN Gabriel; TAPIA RODRIGUEZ, Mauricio (coordinadores): Estudios sobre la Nueva Ley de Acuerdo de Unión Civil. Santiago de Chile: Editorial Thomson Reuters, 2016

HISTORIA de la Ley 20.830. Biblioteca del Congreso Nacional de Chile. Disponível em:

file:///E:/CONPEDI\%20BRAS\%C3\%8DLIA/historia\%20de\%20la\%20ley\%20chile.pdf. Acesso em 15.abr.2017.

MAIA JUNIOR, Mairan Gonçalves. A família e a questão patrimonial: planejamento patrimonial,r egime de bens, pacto antenupcial, contrato patrimonial da união estável. São Paulo: Revista dos Tribunais, 2015. 
MARTEL, Frèdèric. Global Gay: Cómo la revolución gay está cambiando el mundo. Madrid: Editorial Taurus, 2013.

OLIVEIRA, Euclides Benedito de. União estável: do concubinato ao casamento. São Paulo: Método, 2003.

ORREGO, Juan Ándres. Apunte de Derecho de Familia. Disponível em: https://www.juanandresorrego.cl/apuntes/derecho-de-familia/. Acesso em: 10.mar.2017. 